\title{
MARIO VARGAS LLOSA: INTERSTICIOS DE LA HISTORIA
}

\begin{abstract}
Alicia Borinsky
A través de una lectura detallada de las estrategias narrativas en La tía Julia y el escribidor, Historia de Mayta, Lituma en los Andes y El sueño del celta, en este artículo se dirimen cuestiones acerca de la construcción de la verdad en las novelas y el discurso histórico, asignando un papel preponderante a temas de género.
\end{abstract}

Alicia BorinSKy. Es catedrática de literatura latinoamericana y comparada de la Universidad de Boston y directora del programa de estudios culturales en Buenos Aires de la misma entidad. Es autora de numerosos libros y artículos. Sus obras más recientes son Frívolas y pecadoras/Frivolous Women and Other Sinners (Swan Isle Press, 2010) publicada en forma bilingüe, y One Way Tickets: Writers and the Culture of Exile (Trinity University Press, 2011). Ha recibido varios premios, entre ellos el Latino Literary Award for Fiction y la beca Guggenheim. Aborinsky@gmail.com.

Estudios Públicos, 122 (otoño 2011). 
$\mathrm{E}_{1}$ discurso histórico canibaliza a los individuos. Su teleología arrasa con lo cotidiano, las dudas, el claroscuro de la vida. El fulgor de nuestras incertidumbres desaparece cuando deviene obstáculo para metas establecidas y el afán programático señala que no hay espacios para la ironía o el titubeo.

La corrupción, los múltiples engaños de quienes detentan el poder ha generado una gran desconfianza en el público. ¿Dónde encontrar aunque sea un amago de verdad que nos rescate de la prensa sensacionalista y las versiones tendenciosas de los hechos? ¿Dónde y cómo buscar la verdad de nuestra memoria colectiva?

La popularidad de las novelas basadas en hechos reales presentados desde la perspectiva de una investigación cumple el papel de llenar el vacío de autoridad suscitado por la desconfianza en los medios de comunicación ya sean oficiales u opositores. El hartazgo de las censuras que primaron en Latinoamérica desde fines de los sesenta hasta los ochenta abrió el camino para la novela periodística, un género que se autopresenta como objetivo, sin apremios ideológicos y que se beneficia del hecho de que los lectores latinoamericanos hayan debido acostumbrarse a que el rumor fuera una forma de comunicación más confiable que los periódicos durante toda una época. Los grupos revolucionarios que operaron en la clandestinidad sumaron el secreto, la idea - plantada por los represores y confirmada por las persecuciones - de que detrás de la vida cotidiana había otra que sólo de vez en cuando se manifestaba frente a la gente común con hechos alternativamente vistos como heroicos o criminales.

El rumor devino en esas circunstancias una práctica casi necesaria para obtener información. Comunicarse a través de rumores implica cierto escepticismo con respecto a las fuentes de la información, el reconocimiento de que la posición de quien habla redefine lo dicho.

El género de aquello que Tomás Eloy Martínez llamó "ficciones verdaderas" obtuvo popularidad como resultado de la desconfianza en los medios tradicionales. Su Santa Evita da una versión tan persuasiva de la historia de Eva Perón a través de los itinerarios por los que viajó su cadáver, que algunas de las circunstancias inventadas como parte de la novela son ahora consideradas parte de la realidad histórica.

Hay frecuentemente periodistas que aparecen como personajes en novelas donde explican e investigan hechos suficientemente cerca- 
nos a la realidad como para dar la ilusión de que están escribiendo algo transparente, verdadero. Varias novelas de Mario Vargas Llosa hacen participar al lector en una investigación. Lo invitan a armar las referencias que lee y ser consciente de las limitaciones de la visión que les da sentido.

La coherencia novelística explica y ordena lo arbitrario y parece internarse en zonas secretas para iluminarlas. Por eso es un género capaz de presentar la verdad para una comunidad interpretativa acostumbrada a reconocer que es a través de la ficción que entrevemos la realidad.

\section{El cuarto / la intimidad}

[C]uartos a la deriva / en ciudades que se van a pique. (Octavio Paz, "La estación violenta”, Libertad bajo palabra.)

Historia de Mayta $^{1}$ es una novela que despliega la posibilidad de dos lecturas, con una que ocupa el mayor número de sus páginas $\mathrm{y}$ otra que sugiere una revisión de lo leído a partir de un punto de vista diferente. En ambas se dirime la cuestión de género y se sopesan alternativas de virilidad.

Alejandro Mayta es un guerrillero cuya homosexualidad sólo se concreta secretamente de modos transgresivos. La novela lo representa recortado de su entorno, incapacitado de suscitar una solidaridad que lo ayude a vivir tanto entre sus compañeros de izquierda como en el medio de derecha. Mientras que en El beso de la mujer araña Manuel Puig fortifica al personaje de Molina con los atributos de un estilo más allá del género atribuyéndole lo mejor de las mujeres marcadas de Hollywood y Severo Sarduy inventa una dicción paródica que sugiere que la escritura es un juego donde uno apuesta la estabilidad de las distinciones de género, Vargas Llosa tiene como protagonista a una sociedad que aísla a Mayta.

Sarduy asedia el fulgor barroco de una diferencia que aun en la enfermedad - como en Pájaros en la playa - se autorrepresenta alternativamente como desfile de modas y tentación humorística. Puig genera el contagio de las voces de las mujeres de la clase media argen-

${ }^{1}$ La paginación corresponde a la primera edición de Historia de Mayta (Seix Barral), 1984. 
tina y nos lo brinda como hipótesis de traducción de una sexualidad que aunque se atilde con el lujo de las divas hollywoodenses adquiere la simplicidad de la vida cotidiana de clase media en clave femenina. Estas escrituras conciben al género en un espacio en el cual el cuerpo se presenta en una performance que puede llegar a ocultar el espacio mayoritario. La muerte de Molina en El beso de la mujer araña confirma que ha triunfado una femineidad sufriente donde un hombre logra cumplir su destino de mujer abnegada, hecha para el amor y sacrificada por la política.

Conocemos a Mayta a través de un secreto mediocre. Su esposa ve cómo se despide de un amante y lo percibe revelando su propia perspectiva. Obscena en su chatura, su reacción la exhibe tanto como a Mayta:

Por la ventana vio el auto: en la luz azulosa del amanecer bajaba la silueta sin cara de Mayta, y, por el otro lado, el chofer. Volvía a la cama cuando algo insólito, difícil de explicar, de definir, la desasosegó. Retuvo la cara pegada al cristal porque el otro había hecho un movimiento para despedirse de Mayta que no le pareció normal tratándose de su marido. [...] El tipo como despidiéndose le había cogido la bragueta. Se la tenía cogida todavía y Mayta, en vez de apartarla [...] se había ido contra él. (Historia de Mayta, p. 211.)

No mira por la ventana, espía. Cuando Mayta sube a la habitación no menciona lo ocurrido y ella finge dormir. ¿Qué ve la mujer cuando espía? Su mirada convierte la información que obtiene en una mentira que se dice a sí misma. No le menciona nada a Mayta cuando llega a la cama para acostarse con ella. Atesora la escena y se la apropia como un modo de distanciamiento. Está fuera de discusión porque conversar sobre eso en el momento mismo en que había sucedido, precipitaría la posibilidad de una intimidad ausente en la pareja.

El entusiasmo sexual de su marido por un hombre le causa menos indignación que sorpresa porque el recato de los contactos físicos durante su matrimonio sólo parecían haberle sugerido que esa cosa fría e insatisfactoria entre ellos era una versión de la normalidad. La pareja concebida en esta novela cuida con discreción la calidad del desapego que los une.

El imaginario erótico otorga frecuentemente un papel especial a los revolucionarios cuyas vidas privadas adquieren el exceso y creati- 
vidad de su proyecto político. Incluso Manuel Puig, que en El beso de la mujer araña está muy lejos de adjudicar libertad sexual al militante heterosexual de izquierda Arregui que comparte la celda con Molina, presentado como encarnación de quien — como homosexual— se deja arrastrar por sus pasiones, toma en cuenta el papel liberador de la ideología. En Historia de Mayta, la sociedad vergonzante signa el tono tanto para Mayta como para su mujer.

Ninguno de ellos tiene un ideal amoroso. Son grises, respetuosos, medidos. Si el espiar revela frotamientos y la posibilidad de una lubricidad sorpresiva, su impacto no tiene un correlato lingüístico. El lector debe intuir que existe una parte de Mayta que permanecerá silenciada como un peso que define los límites de su capacidad de cambio.

Secretas, así, son sus actividades políticas y ocultas también las sexuales. Mayta es un clandestino completo. Se sabe en peligro por sus actividades subversivas y siente que no puede confesar su homosexualidad por consideración a un qué dirán social.

El respeto que se afana en lograr al vivir con su mujer es un gesto eminentemente conservador que contradice la confianza que, como revolucionario, debería sentir hacia quienes pretende convencer de que sabe el sentido en que avanza la historia. Mayta es un homosexual vergonzante y un revolucionario fallido.

Como es frecuente en la obra de Mario Vargas Llosa, una serie de preguntas forjan la ilusión de que personajes y lector están en íntima comunicación:

Sentí profundo malestar ¿Hice bien en venir? ¿No era otro gesto sentimental esta visita, sin sentido ni finalidad? ¿No maliciaría Adelaida algo raro? ¿Eso que cantaban era la Internacional en quechua? (Historia de Mayta, p. 205.)

El lector es conminado por estas preguntas a participar, convertirse en voz implícita que se interroga del mismo modo y busca una respuesta. Pero otra representación subyace en ésta: es la de un grupo social que titubea. La interlocución armada por los interrogantes opera un contagio por el cual el lector comparte las limitaciones de quienes así representan sus alternativas. La ventana a través de la cual espía la mujer de Mayta enmarca también a un lector que debe participar en la sensación de que aquello que agita a Mayta es pecaminoso. La mirada de la mujer transmite la proclividad de Mayta como una cuestión de sa- 
lud. La novela nos informa que le ha pedido en su momento que siga el consejo de un médico y se someta a un tratamiento de electroshock para "curarse" ya que sabe que no es meramente un vicioso sino un enfermo. Cuando ella insiste en la idea de la cura, él responde débilmente que no es una cuestión médica.

La mujer no puede aceptar que exista en Mayta un deseo por otros hombres que pueda equipararse con lo que para ella sería la saludable atracción heterosexual. No hay lugar a dudas de que es presentada - como ocurre frecuentemente cuando se trata de personajes femeninos que defienden la institución del matrimonio- como fría y falta de intuición erótica. Pero eso no significa que Mayta sea dignificado por su pasión. Ella se cree traicionada pero no reconoce ningún motivo que impida que él siga siendo su marido si decidiera cambiar.

Mayta es expulsado de su matrimonio y de su partido político. Los detalles de los motivos de expulsión pertenecen hoy a la arqueología de la izquierda de fines de los sesenta a los setenta. Más importante que cualquier desavenencia de orden personal, ser excluido del partido barre con la estructura que permite organizar las prioridades diarias, entender el papel de los afectos.

El estar fuera redefine a Mayta quien siempre había creído que la pertenencia al partido era más importante que lo personal. Su posición se hace eco de las ideas sobre el buen militante que circulaban en la época y eran seguidas con un fervor casi religioso. No formar parte del partido después de haberse sometido a sus reglas y haber logrado organizar su vida de acuerdo con su sistema de prioridades, es experimentado como una forma de muerte. No estar casado es diferente porque la ruptura del vínculo familiar es una liberación. Pero esta parte de la novela no nos deja ver una dimensión de desarrollo de la existencia de Mayta en la cual sin los límites impuestos por su mujer disfrute de su verdadera preferencia.

Respetuoso, tentativo en sus modales, carente de arrogancia, Mayta es retratado como un pobre tipo con grandes ambiciones históricas. No es motivado por ningún deseo de ascenso personal. Priman en él la voluntad de comprender el mundo y el deseo de convencer por medio de su inteligencia.

Las preguntas que se repiten en esta novela construyen una conversación con lectores implícitos y la hipótesis de una vida interior y de elaboración política para los personajes. El “¿qué pensaría Mayta de 
todo esto?" y sus equivalentes guían la lectura con una estrategia que Mario Vargas Llosa usa paródicamente en La tía Julia y el escribidor ${ }^{2}$. Mientras que en Historia de Mayta las preguntas van construyendo un contexto para la vida de Mayta, en La tía Julia y el escribidor son usadas hiperbólicamente para establecer suspenso en las radionovelas intercaladas. La extrema artificialidad de las radionovelas y la naturalidad del discurso en Historia de Mayta tienen un efecto similar: instituyen una sensibilidad de clase media para ordenar y evaluar lo percibido.

La primera lectura de Historia de Mayta es acerca de la cobardía que impide aceptar la homosexualidad y vivir fuera de la disciplina partidaria. La segunda presenta a Mayta al final de una estadía en la cárcel de regreso en Lima. Está casado y tiene cuatro hijos. Es empleado de una heladería, está orgulloso de la calidad de los helados, se desempeña con destreza y, lo que es más importante, es un excelente hombre de familia.

El narrador-personaje que le habla de la novela que ha escrito sobre él lo entrevista acerca de la mezcla de ficciones y verdades que se entremezclan en su relato destacando que inventó la hipótesis de que era homosexual para ubicarlo entre los marginados. En esta nueva lectura, Mayta es como la esposa en la versión anterior. Desprecia la homosexualidad y quiere separarse de cualquier asociación con ella.

El encuentro entre Mayta y Anatolio que cierra la primera lectura: "Ya no somos ni camaradas ni amigos — dijo Mayta—. ¿Qué mierda quieres? - Que me la chupes - dijo el muchacho, despacio, mirándolo a los ojos y tocándole la rodilla con los cinco dedos" (Historia de Mayta, p. 199) contrasta con el Mayta que no puede aceptar la homosexualidad incluso en sus camaradas. Este Mayta se parece a los militares y políticos de derecha que hablan de "mariquitas" y a la esposa despechada que sugiere el electroshock.

La segunda versión se superimpone a la primera sin cambiarla. $\mathrm{Al}$ contrario, la afirma porque aun cuando Mayta sea visto como heterosexual, los términos de la estructura siguen siendo los mismos y una virilidad sofocante margina a los homosexuales. El retrato de Mayta de la segunda versión destaca nuevamente su cortesía, la reserva con que habla de su pasado y el modo en que rehúsa ser visto como un héroe. Mientras que en la primera lectura el investigador que presenta sus

${ }^{2}$ La paginación corresponde a la primera edición de La tía Julia y el escribidor (Seix Barral), 1977. 
materiales al lector está separado de lo que ocurre, en la segunda esa distancia quiere ser borrada con la hipótesis de que Mayta y el narrador han sido condiscípulos.

Están unidos generacionalmente, participaron de las mismas experiencias de juventud y de ese modo desplazan el vínculo entre lector e investigador — personaje al que existe entre ese investigador - personaje y Mayta.

La definición del narrador-personaje como personaje vinculado a Mayta pone entre paréntesis su objetividad al sugerir que el lector estará ahora en la misma situación que la mujer mirando por la ventana en la primera lectura.

El lector se ha quedado solo, sin pacto posible de solidaridad con lo que lee, porque sabe, desde el momento en que se sugiere el vínculo, que todo lo leído es ficción, incluso el discurso que lo enmarca. Como la mujer que mira por la ventana sin mencionar lo que ha visto hasta mucho después, el lector reserva su crítica pero advierte que la proyección en el personaje-investigador ha sido truncada.

El pasaje de la representación de primer grado del narrador-investigador a la de segundo grado, que pertenece a un nivel más profundo de ficción, como si esta vez fuera un dato escondido cuyo secreto es sólo develable por la interpretación, recuerda la lectura que en el extenso libro dedicado a García Márquez — Historia de un deicidio — Vargas Llosa hace de Cien años de soledad señalando esa estrategia.

El dato escondido en el caso de Historia de Mayta es el movimiento de una lectura a otra que permite quitarle autoridad a uno de los sentidos del relato para recomendar una lectura dubitativa de sus propias conclusiones.

Uno de los elementos permanece constante y se presenta como interrogante. ¿Por qué presentar la homosexualidad como la fluctuación que define al Mayta más "verdadero" de la segunda lectura como algo rechazado que lo identifica con los sectores conservadores de la sociedad?

El machismo de la izquierda latinoamericana de esos años es parte integral del relato y al equiparar las opiniones de Mayta con las de derecha, surge el cuadro de una sociedad sexualmente homogénea. Los guardias de la cárcel en la cual estuvo preso Mayta comparten con los presos el deseo de torturar y explotar a los homosexuales, el sometimiento a apremios sexuales y la humillación a través de ellos es parte 
de la admisión en el teatro de poder carcelario. El motivo por el cual Mayta está en la cárcel contribuye también a forjar la visión de una sociedad con pocas alternativas de cambio.

Una complicada red de engaños y delaciones implica a Mayta en una serie de actos criminales que no ha cometido. Lo principal es que ha participado en algo que creía eran expropiaciones que se convirtieron - sin que se diera cuenta - en robos. Persona descartable entre sus camaradas, es señalado por uno de ellos y paga por un crimen que no cometió. De este modo, Mayta es ingenuo en cuanto a sus opiniones políticas y - en ambas lecturas - reacio a incurrir riesgos en sus actividades eróticas.

Doblemente condenado por la sociedad que lo excluye y los camaradas que no sólo lo denuncian sino que también lo desilusionan por su falta de principios, Mayta queda solo. El rechazo de la homosexualidad es el vínculo que lo une a su momento histórico y lo ubica en un lugar específico.

El narrador-investigador dice haber inventado ser condiscípulo de Mayta. Esa hipótesis enmarca una conversación entre los miembros de la pareja investigador-protagonista que tiene una relación más estrecha con lo extraliterario que los estratos anteriores de la novela. En ella Mayta asegura carecer de prejuicios excepto en el caso de los homosexuales. Al describir la razón del rechazo que siente con respecto a ellos, su lenguaje cambia y va de la parquedad de palabras a un derroche expresivo. Es como si Mayta, de pronto, adquiriera elocuencia. Se separa de los homosexuales y explica su asco no por ignorancia sino por familiaridad:

-Nunca tuve prejuicios sobre nada - murmura, luego de un silencio- . Pero sobre los maricas, creo que tengo. Después de haberlos visto. En el Sexto, en el Frontón. En Lugarincho es todavía peor.

Queda un rato pensativo. La mueca de disgusto se atenúa, sin desaparecer. No hay asomo de compasión en lo que dice:

-Depilándose las cejas, rizándose las pestañas con fósforos quemados, pintándose la boca, poniéndose faldas, inventándose pelucas, haciéndose explotar igualito que las putas por los cafiches. Cómo no tener vómitos. Parece mentira que el ser humano pueda rebajarse así. Mariquitas que le chupan el pájaro a cualquiera por un simple pucho... - Resopla, con la frente nuevamente llena de sudor. Agrega entre dientes 
— dicen que Mao fusiló a todos los que había en China. ¿Será cierto?" (Historia de Mayta, p. 336).

Quien habla es un Mayta disminuido por una dolencia que le hace ir a mear a cada rato. A veces se orina en el largo viaje a su trabajo pero las referencias a su estado no le impiden asumir una posición de superioridad para despreciar a los mariquitas. Asco, condescendencia, certidumbre de que se está delante del vicio unen aquí a Mayta con la versión que presentaba a su primera esposa espiándolo por la ventana. Mientras que las palabras que se intercambian son parcas o inexistentes, las otras son ricas en énfasis y resonancias. El rechazo por la homosexualidad da elocuencia a la novela y ordena su registro erótico en clave de rechazo.

¿Y qué sucede con la pareja narrador-investigador y Mayta? ¿Cuál es la posición de quien escucha y transmite? La novela sugiere una interpretación literal cuando la conversación termina con un viaje en auto hacia la casa donde vive Mayta, una vivienda precaria en uno de los lugares más pobres de las afueras de Lima. Pero dejar a Mayta allí no es suficiente. Hace falta que el narrador se desprenda de la estela, del aura en torno a Mayta. Las traiciones, los intrincados caminos de la política con nombres de la época — como el de Hugo Blanco- ya han abandonado la novela integrándose a los materiales que dominan el final: la basura que está invadiendo Lima.

Nada ni nadie está a salvo de transformarse en basura. La novela ha despojado a Mayta de convicción histórica y actividades políticas. En un giro siniestro, la pasión con que Mayta se asquea de los homosexuales lo acerca con un abrazo implícito a la primera mujer que sentía rechazo por la escena que contempla por la ventana.

Esa primera esposa y Mayta son ahora contemplados por el narrador-investigador que se ha hecho amigo del lector y del personaje. $Y$ en esa interlocución fantasmagórica, en esa conversación implícita en el pacto de la lectura, ambos aseguran que lo que hemos espiado desde nuestra ventana es precisamente el proceso de mutación de las referencias de la novela en basura. Todo es cancelado en esta obra: los programas políticos desembocan en engaños delictivos y la sexualidad es filtrada por la óptica del asco.

Mayta quería hacer la revolución pero termina como un patético enfermo compartiendo los prejuicios sexuales de los más objetables 
sectores de la sociedad. Ha sido llevado a su casa, por más modesta que sea, en auto.

El lector, en cambio, se queda a pie en un mundo asfixiante y apocalíptico.

\section{Antídoto: sentimientos y melodrama}

But I had always felt nuts, not romantic.

Too angry to be smooth ${ }^{3}$. (John Waters, Role Models, 2010, p. 5.)

La parquedad de Mayta desaparece cuando la sociedad habla a través suyo en el lenguaje del asco. El modo en que se refiere a la homosexualidad al final de la novela da otra dimensión a la mediocridad de sus sentimientos. Es capaz de sentir un profundo rechazo.

Una relectura de La tía Julia y el escribidor nos la revela como un laboratorio de estrategias para representar sentimientos así como para la invención de un personaje que va guiando la lectura al mismo tiempo que revela sus propias peripecias. Al fin de Historia de Mayta, el protagonista parece sufrir un contagio del lenguaje de la clase media que lo ventriloquiza; La tía Julia y el escribidor concibe a la radio como la voz de esa hipérbole y trata de nombrar a los sectores que ella representa.

Es inevitable reconocer ecos de la obra de Manuel Puig en esta novela por su pasión por la cultura popular y - sobre todo- en la idea de que la interioridad de los personajes está hecha de un afuera cuyo guión es ajeno.

En la obra hay dos estaciones de radio diametralmente diferentes. Una, la Panamericana, pasa jazz, algo de música clásica, noticias y tiene locutores con dicciones "casi argentinas". Su sede está en un edificio moderno. La otra, la Central, transmite desde una casa criolla llena de vericuetos programas de música peruana dirigidos por locutores que hablan en la jerga popular. Algunos de los artistas que allí trabajan son tan populares que a veces se concentra el público en las puertas para verlos entrar.

La oposición entre el esnobismo concebido a la argentina y la vernácula fiesta populachera se hace con ironía ya que Marito, el narra-

3 "Pero siempre me sentí más alocado que romántico. Demasiado enojado para fingir serenidad" (traducción mía). 
dor y persona autobiográfica, es parte del personal de la sección noticias de la Panamericana. No falta el comentario sociológico que nos asegura que ambas emisoras tienen el mismo dueño.

Las dos estaciones de radio pertenecían al mismo dueño y eran vecinas, en la calle Belén, muy cerca de la Plaza San Martín. No se parecían en nada. Más bien, como esas hermanas de tragedia que han nacido, una, llena de gracia y, la otra, de defectos, se distinguían por sus contrastes. (La tía Julia y el escribidor, pp. 11-12.)

Los dos públicos de las emisoras son suplementados por dos escritores diferentes: Marito cuyos proyectos son convencionalmente literarios y Pedro Camacho, autor de radionovelas que trabaja un género a la vez complicado e híbrido.

Camacho, boliviano, fascina a radioescuchas de todas las clases sociales. Sus novelas son intensas, exageradas; transmiten y suscitan pasión. Le anima un profundo rechazo hacia los argentinos que incluso lo lleva a amenazar con abandonar su puesto si no despiden a unos empleados de esa nacionalidad. Para él la radio debe acompañar sus creaciones.

Ciertos autores de radioteatro en América Latina como Nené Cascallar y Alberto Migré alcanzaron grandes audiencias, sobre todo femeninas, y, en un contexto mucho más íntimo que el de las salas cinematográficas, brindaron un hilo conductor para que existencias mediocres fueran concebidas en términos dramáticos y sentimentales. Pedro Camacho es uno de ellos. En La tía Julia y el escribidor se intercalan radionovelas que se alternan con la historia del romance de Marito con su tía Julia. El lector entra en un juego que le exige elegir entre los dos relatos: ¿Mejor saltarse lo de Marito y seguir con la novela o viceversa?

Las lecturas alternativas entraron a la literatura latinoamericana a partir de los dos modos de encarar el libro sugeridos en Rayuela de Julio Cortázar y llegan a adquirir gran intensidad en El beso de la mujer araña de Manuel Puig donde las notas al pie sugieren una interpretación sintomática del texto que amenaza con acabar con la proyección del lector en los destinos de los dos protagonistas encerrados en la cárcel. En La tía Julia y el escribidor el tono es ligero pero lo narrado es hiperbólico. 
El amor de Marito por su tía Julia tiene visos incestuosos y transgresivos ya que ella también lo aventaja mucho en edad; Pedro Camacho, a pesar del género al que se dedica, baraja destinos que lo incluyen en su registro. De Marito conocemos detalles que constituyen su vida con informaciones transmitidas en forma lineal. Pedro Camacho se da a conocer intermitentemente. El lector es público de sus radioteatros y advierte que está enloqueciendo cuando los personajes empiezan a mezclarse.

El conflicto entre los dos modos diferentes de narrar se resuelve a favor del de Camacho porque la calidad de la historia de Marito es la de un radioteatro y la vida de Camacho tiene todo el misterio de sus creaciones. Su odio antiargentino se explica al final por un conflicto con su mujer, una argentina que lo dejó para putear, como en un tango. Y también como en un tango, es abnegada y él la perdona al final:

Ya habían estado casados — me dijo Pascual, mientras se desarremangaba la camisa y se ponía el saco y la corbata—. Allá en Bolivia, antes de que Pedrito viniera a Lima. Parece que ella lo dejó, para irse a putear por ahí. Se juntaron de nuevo cuando lo del manicomio. Por eso se pasa la vida diciendo que es una señora tan abnegada. Porque se juntó otra vez con él cuando estaba loco. (La tía Julia y el escribidor, p. 445.)

Según uno de los personajes, le tiene un agradecimiento de perro porque ella lo mantiene. La novela acentúa la humillación de Camacho. Es un mantenido con una existencia más rastrera que cualquiera de sus invenciones. La suma de sus carencias hace de él un personaje hiperbólicamente débil. Marito, en cambio, es un triunfador.

Condescendencia, desprecio, hilaridad enmarcan la aparición final de Camacho. Como sucedería más adelante en Historia de Mayta, en la hipótesis que concibe al narrador-investigador como condiscípulo de Mayta, aquí Marito es colega de Camacho.

Uno y otro representan versiones factibles de su opuesto al encarnar diversas posibilidades novelísticas. Entrar y salir de la ficción, ser parte de la ficción como personaje y saltar a otro nivel de representación para fingir estar afuera: La tía Julia y el escribidor postula que la primera pareja de este tipo en la obra de Vargas Llosa precisa de la humillación de uno para destacar el triunfo del otro. 
¿En qué reside ese triunfo y qué modelo de escritura privilegia? Marito encarna el momento explícitamente autobiográfico de la obra. Con un guiño al lector invita a olvidar la ficción para ceder el paso a la realidad donde el nombre del personaje, Marito, coincide con el del autor de la obra. Asediado por los efectos de ficción el nombre de Marito se contagia del efectuado por Camacho y la historia de su romance es percibida como parte del radioteatro.

La primera esposa de Mayta habla en el idioma de la clase media baja con una perspectiva prejuiciosa que la acerca a la de las clases altas, el lenguaje de Marito aparentemente diferente del de Camacho por ser más medido se contagia de sus hipérboles. Los opuestos se confunden, entremezclan y sólo se separan ilusoriamente.

Como en el caso de las dos emisoras de principios contrastantes, los personajes revelan su mismidad. La parquedad de Mayta, el misterio de sus sentimientos que sólo se avivan cuando habla de su odio contra los homosexuales lo acerca al lenguaje melodramático de los afectos en las radionovelas en un giro irónico hecho posible por la lectura superimpuesta de La tía Julia y el escribidor.

¿Cuál es el resto novelístico, eso que nos deja pensando en el personaje después de terminar la obra? ¿A quién queremos encontrar a la vuelta de la esquina? Cortázar le otorga ese encanto a la Maga en Rayuela. Es ella quien sigue construyendo la novela para nosotros fuera de las tapas del libro. Ese logro por el cual lo inventado construye versiones fuera de la obra se cumple en Historia de Mayta con la vida del protagonista. Queremos seguir pensando en el destino de las izquierdas, sopesar sus logros y fracasos, conocer la vida familiar de Mayta y saber si es cierto que la segunda lectura sobredetermina la primera que lo muestra homosexual. Cualquiera sea la preferencia sexual de Mayta, su existencia es el secreto que da vida a la novela porque reconocemos que el investigador-personaje no acaba cuando cerramos el libro. Nos deja la tarea de seguir escribiéndolo.

La tía Julia y el escribidor no agota a ninguno de los personajes, los mantiene a la par. Estamos tan interesados en Marito como en Camacho. Uno posee la atracción de una carrera literaria que debe concretarse y la energía de aventura de un universo que pertenece a la esfera de la claridad de metas personales. El otro nos brinda olores, desechos, plagios, enfermedad mental en la fértil oscuridad del lumpenaje. 
Camacho es una de las basuras que invaden la ciudad en Historia de Mayta. Su fracaso es la persistencia de la relación con esa argentina a quien ama más allá de la dignidad con una pasión que los convierte en tristes figuras tangueras. La extrema pobreza de Mayta, personaje de barrio miserable y precario y la de Camacho, unida en su caso a problemas psicológicos, son los componentes del aura que insiste en que prosigamos la lectura más allá del libro.

Los personajes investigadores son marco, proyección implícita del lector y se borran después de haberles persuadido de realizar la tarea que ellos comenzaron. Basura y lumpenaje son aristas de la indignación que suma versiones en un pacto renovado con el lector.

\section{La celda}

L'homme oblique prend nos grilles en écharpe, désarme les anthithéses, remplace le ou par le et $t^{4}$. (Regis Debray, Loués soient nos seigneurs)

En Lituma en los Andes ${ }^{5}$ el misterio de la violencia encierra a quienes de mala gana tratan de investigarla. Lituma y su ayudante generan cierta solidaridad en el lector debido a que el relato - como es frecuente en tantas obras de Vargas Llosa - presenta los sucesos con abundantes citas de las voces de los personajes. En ese sentido, la novela parece ser hablada, casi un radioteatro. El habla crea un contexto en el cual el lector es incluido en una conversación imaginaria que le convierte en cómplice de Lituma. También él desea saber, investigar. Esta vez no se trata de la vida de un personaje como en Historia de Mayta sino acerca de un suceso que nadie desea analizar. El miedo a las consecuencias en la forma de muertes y torturas azuzado por rumores y el mero sentido común que hace que prime la autoprotección, aísla a los militares que necesitan información.

Lituma no forma parte de la comunidad que pretende investigar. Los indígenas son un enigma, la guerrilla, otro, y la gente del pueblo no confía en ninguna protección distinta de la propia. Es decir, el silencio.

4 "El hombre oblicuo se burla de nuestras distinciones, desmantela las antítesis, reemplaza el o por el y" (traducción mía), Loués soient nos seigneurs, 1996, p. 415. 1993.

${ }^{5}$ La paginación se hace de acuerdo con la primera edición (Planeta), 
Los secretos de Mayta son tácticos, el de Camacho es la reserva implícita en la enfermedad mental, el del pueblo es un ejemplo de la falta de contacto cultural. Lituma está tan distanciado de aquellos a quienes vigila que es como si una celda invisible lo rodeara. No puede salir de su ignorancia, encontrar un punto de referencia para sus acciones, inventarse un modo de actuar:

Lituma leyó y releyó, descorazonado, el telegrama. Eso decía. En esa mina estaban mejor equipados que en este campamento cochambroso. Él aquí estaba incomunicado, ciego y sordo a lo que ocurría en el mundo exterior. Porque la radio del campamento funcionaba tarde, mal y nunca. (Lituma en los Andes, p. 147).

Realizar una misión en este pueblo es como intervenir en un país extranjero cuyo idioma fuera desconocido. A contracorriente de las ideologías triunfalistas que celebran el multiculturalismo, la realidad peruana que aquí se retrata está hecha de estratos discontinuos y hostiles. Países diferentes, trabajosamente combinados se cierran para ocultarse con el afán de sobrevivir. Y cuando se conectan, lo hacen a través de lo grotesco. Lituma y su adjunto están encerrados por la información; el narrador refleja la mirada con que ven a quienes los rodean cuando describe a una mujer a quien llaman la bruja. Esta descripción acerca el imaginario de Vargas Llosa al que se intuye en la literatura regionalista - como Huasipungo - que desde sus inicios presentó las posibilidades decadentes de la distancia y el aislamiento. El cuerpo de la mujer cuya juventud quedó atrás está pleno de posibilidades de historias, intimación de un pasado cuya construcción interpreta el lugar donde está. La pregunta es ¿cómo llegó a ser de esta manera? La mujer es la herida por la cual se presenta el nivel de decadencia del pueblo:

De día preparaba comida para algunos peones, y en las tardes y las noches, les adivinaba la suerte con naipes, cartas astrológicas, leyéndoles las manos o tirando al aire hojas de coca e interpretando las figuras que formaban al caer. Era una mujer de ojos grandes, saltados y quemantes, y unas caderas ampulosas que columpiaba al andar. Había sido una real hembra al parecer y se decían muchas fantasías sobre su pasado. [...] Lituma sospechaba que, además de cocinera era también otra cosa. (Lituma en los Andes, p. 38). 
Como la esposa de Camacho, esta mujer está gastada y es probablemente prostituta. Su destino se ve sin compasión porque su deterioro es una afrenta para los hombres que la contemplan. La primera esposa de Mayta al espiar por la ventana es enmarcada por su propia mirada y deviene una de las características que constituyen a Mayta en perdedor. Lituma restringido sexualmente a las conversaciones con su adjunto lleva una existencia nostálgica y pobre. Esta mujer es parte de su celda.

La celda de afuera figura en la obra de Vargas Llosa como un modo de asegurarnos que las incertidumbres de interpretación, la ignorancia de los bordes que separan a una cultura de otra son limitaciones a la libertad cuyas consecuencias son tan radicales como las celdas de adentro en las cárceles convencionales.

Lituma está separado de quienes investiga por sus objetivos ideológicos y la representación del gobierno de turno asegura que, por lo menos oficialmente, lucha en contra de la guerrilla y la violencia de los narcos. Su pertenencia nacional no se pone en duda aun cuando sea como turista de un país extranjero en el lejano reducto peruano donde opera.

En una celda real (El sueño del celta ${ }^{6}$ ) Roger Casement aguarda una sentencia que seguramente será de muerte. Roger Casement estuvo más allá del oportunismo político. Los oportunistas cambian de opinión para acomodarse. Son guiados por el deseo de autoprotección. La vasta galería de oportunistas incluye a revolucionarios que desisten de sus actividades y se unen al gobierno de turno, funcionarios que sirven desde siempre a quien esté ahí, individuos que contentos de ver desaparecer a parte de una población vista como subversiva, celebran después los juicios a los asesinos y se dicen eternos defensores de los derechos humanos. Estos y muchos otros preservan vivas las alternativas ofrecidas por el momento y cambian de papel en una estructura con el afán de persistir.

El oportunista necesita información, tiene que estar al día porque es condición necesaria para saber cómo actuar, con quién congraciarse. Para el oportunista los cambios históricos exigen respuesta inmediata. Su talento de camaleón y la carencia de convicciones éticas le permiten delatar o simplemente integrarse a la vida cotidiana haciéndose eco de las opiniones mayoritarias. A veces cuando los políticos son acusados

${ }^{6}$ La paginación corresponde a la primera edición (Alfaguara), 2010. 
de oportunismo es como parte de una exigencia de adhesión a ideas que han dejado de lado por motivos diferentes de los de beneficio personal.

El caso de Roger Casement, galardonado por el mismo país - Inglaterra - que lo enviará a la horca en 1916 muestra cómo un cambio radical y honesto puede llevar a tomar posiciones opuestas. Como en un cuento de Borges, el héroe Casement se convierte en traidor.

Casement fue un escritor prolífico y un cronista de atentados a los derechos humanos en el Congo y Perú. El destino de Casement y su final se barajan en términos nacionalistas. Inglaterra lo consideró un patriota antes de verlo como traidor e Irlanda lo celebra como héroe de la nación. Casement, huérfano de madre desde los nueve años y de padre desde los trece, tuvo un origen doble ya que a pesar de que fue criado como protestante por sus tíos, su madre lo bautizó en secreto como católico a los tres años. La adhesión tanto a Inglaterra como a Irlanda aparece desde esta perspectiva más como aceptación de sus orígenes que como cambio escandaloso.

La vida de Casement es ejemplo de un estado de alerta especial, de un dejar de lado ideas preconcebidas acerca de los derechos de Europa sobre territorios vistos bajo la óptica de explotación colonial para señalar las profundas consecuencias que de allí surgen.

La vida de Casement es reconstruida en la novela desde la celda en la cual espera sentencia. Allí no llegan noticias, sólo rumores, alguna que otra visita pero, sin embargo, Casement está más libre que Lituma en la celda de afuera porque entiende cuál es su papel en el mundo. Vargas Llosa traza los cambios en Casement sin incurrir en el sensacionalismo ni adjudicarles motivos psicológicos. Al contrario, la radicalidad de ir de una posición a otra y de la defensa de un país a un ataque tienen la coherencia de un ejercicio de libertad y apertura. La solidaridad con naciones diferentes se apoya en ideales que permanecen firmes. Vargas Llosa hace decir a Mayta en la segunda lectura de la novela que nunca tomó la decisión de dejar la política sino que ésta se le fue desdibujando. Casement no vive su cambio del mismo modo, la política permanece vigente aun cuando no entienda completamente los motivos por los cuales el tribunal tiene prejuicios en contra de su apelación.

Los rumores que circulan en torno a su persona se refieren a las actividades homosexuales que habría realizado secretamente y de las cuales dejó constancia en unos diarios que fueron llamados black diaries. Aun cuando sus partidarios sostuvieron que eran apócrifos su 
autenticidad parece haber sido probada. La novela utiliza los contenidos de estos diarios y dota a Casement de otro secreto, esta vez inasimilable por la política, un secreto que resta en vez de sumar porque demuestra que es posible que haya sido pederasta. La entropía que trae este secreto se transforma en su opuesto cuando consideramos el peso que le agrega a Casement como personaje.

Queda flotando en la novela, al revés del de Mayta que es dejado de lado para hacerle entrar en una mayoría anónima y deslucida. La voluptuosidad de estos encuentros rescata a Casement del peligro de ser héroe unívoco.

El sueño del celta dibuja a Casement en una celda donde ejerce su libertad. El resto, el suplemento que la novela otorga a sus personajes para que el lector siga inventándolos nos remite a ese otro archivo narrativo constructor de ilusiones de verdad: el de la historia. Es una novela de archivo y la pareja implícita entre sus tapas es la de Casement $\mathrm{y}$ un lector que quiere emular al narrador y seguir investigando.

Uno de esos caminos conduce a Irlanda y la perplejidad ante el monumento erigido en memoria de un hombre oblicuo se vislumbra en los intersticios de la historia. Con estos personajes y situaciones Mario Vargas Llosa ha ido construyendo una mirada a través de las rendijas del gran discurso de la historia para dar vida a una intimidad que de vez en cuando logra superar el adocenamiento de lo unívoco y favorece lo minúsculo que atesoran secretamente los monumentos de aquí y allá.

\section{REFERENCIAS BIBLIOGRÁFICAS}

Debray, Regis. Loués soient nos seigneurs. Paris: Gallimard, 1996.

Paz, Octavio. "La estación violenta". Libertad bajo palabra. México: Fondo de Cultura, 1960.

Vargas Llosa, Mario. La tía Julia y el escribidor. Barcelona: Seix Barral, primera edición, 1977.

Historia de Mayta. Barcelona: Seix Barral, primera edición, 1984.
Lituma en los Andes. Madrid: Planeta, primera edición, 1993. El sueño del celta. México: Alfaguara, 2010.

Waters, John. Role Models. New York: Farrar Strauss, 2010. 